https://doi.org/10.29013/AJT-20-5.6-54-59

Rakhmatova Guzal Botirovna, Senior lecturer in Karshi Engineering Economics Institute, Uzbekistan, Karshi

E-mail:raxmatova85guzal@mail.ru Kurbanov Mingnikul Jumagulovich, Doctor of Chemistry Karshi State University Uzbekistan, Karshi

E-mail:kurbanovmj@mail.ru

Turabayeva Nargisa Bekmuradovna, Senior lecturer in Karshi Engineering Economics Institute, Uzbekistan, Karshi E-mail: turabayeva75nargisa@mail.ru

Tursunova Gulnoza Qaxxarovna, Senior lecturer in Karshi Engineering Economics Institute Uzbekistan, Karshi

E-mail: tursunovagulnoza@ mail.ru

\title{
STUDY OF INSPACTIVE PROPERTIES AGAINST CORROSION OF $\alpha$-AMINOCETONES AND THEIR PRODUCTS
}

\begin{abstract}
The paper examines the anti-corrosion inhibitory properties of a-aminocetones such as thiainan and thiachromane. $15 \% \mathrm{HCl}, 20 \% \mathrm{H}_{2} \mathrm{SO} 4,1 \mathrm{M} \mathrm{HCl}$ and $1 \mathrm{M} \mathrm{H}_{2} \mathrm{SO} 4$ solutions were used as the aggressive medium. As the concentration of the studied compounds in solution increases, so does their protective effect. The increase in temperature showed an increase in the inhibition rate of the inhibitors during the corrosion process. Inhibitors containing morpholine fragment as the most effective inhibitor in aggressive environments were found to have higher inhibition rates.

Keywords: benzothiophene, thiainden, thiaindane, thiochroman, hydrochloric acid, sulfuric acid.

Corrosion of various industrial goods and construction materials made of steel around the world due to corrosion is considered to be one of the most urgent problems today. This is causing great economic and environmental damage to any country. It is therefore attracting the attention of chemists, technologists and scientists dealing with socio-economic problems all over the world. In addition, the decline in efficiency in gas and oil refining, gas and oil refineries, which are the mainstays of any country's economy and strategic

priorities, undermines the operation of the plant as a whole.

The use of organic-based inhibitors in addressing the above-mentioned global problem is currently yielding good results. The use of corrosion inhibitors is one of the most effective ways to prevent the corrosion process [1, 16657-16668]. Research on inhibitors of metal corrosion is a long-term important investment and is of strategic importance from an economic and environmental point of view. The world community is conducting international re-
\end{abstract}


search on the development of toxicologically nontoxic, biodegradable and highly effective inhibitors of corrosion protection of metals, in-depth study of the physicochemical aspects of protective coatings for corrosion protection of metals [2, 82-95].

In studying the anticorrosive properties of the synthesized compounds, we initially used the gravimetric (gravity) analysis method. This method is simple in nature in determining the degree of corrosion of metals, the method is one of the methods that does not require complex and expensive equipment and can provide a very large amount of data, and has not lost its relevance to date.

In this study, the inhibitory properties of the following synthesized compounds were studied at different temperature ranges and concentrations of different aggressive media. For the study, a-piperidino-5-acetyl-2-methyl-1-thiaine (AIT-1), a-morphalino-5-acetyl-2-methyl-1-thiaine (AIT-2), a-piperidino-6- acetyl-1-thiochroman (AIT-3) and $\alpha$-morphalino-6-acetyl-1-thiochroman(AIT).

Table 1.

\begin{tabular}{|c|c|c|c|c|c|c|c|c|}
\hline \multirow{2}{*}{$\begin{array}{l}\text { Ingib. } \\
\text { cipher }\end{array}$} & \multirow{2}{*}{$\begin{array}{c}\text { Ingib. } \\
\text { amount mg/l }\end{array}$} & \multirow{2}{*}{$\begin{array}{l}\text { Time, } \\
\text { hour }\end{array}$} & \multicolumn{3}{|c|}{$15 \% \mathrm{HCl}$} & \multicolumn{3}{|c|}{$20 \% \mathrm{H}_{2} \mathrm{SO}_{4}$} \\
\hline & & & $\mathbf{K}_{\mathrm{r} / \mathrm{M}^{2} \mathrm{q}}$ & $\gamma$ & Z\% & $\mathbf{K}_{\mathrm{r} / \mathrm{M}^{2} \mathrm{q}}$ & $\gamma$ & Z\% \\
\hline 1 & 2 & 3 & 4 & 5 & 6 & 7 & 8 & 9 \\
\hline \multirow{15}{*}{ AIT -1} & \multirow{3}{*}{50} & 2 & 0.84 & 23.80 & 95.80 & 1.84 & 16.64 & 93.99 \\
\hline & & 4 & 0.89 & 23.59 & 95.76 & 0.97 & 30.61 & 96.73 \\
\hline & & 6 & 0.84 & 27.26 & 96.33 & 0.95 & 31.78 & 96.85 \\
\hline & \multirow{3}{*}{100} & 2 & 0.46 & 43.47 & 97.70 & 0.87 & 35.97 & 97.22 \\
\hline & & 4 & - & - & - & 0.93 & 31.93 & 96.86 \\
\hline & & 6 & - & - & - & 0.92 & 32.82 & 96.95 \\
\hline & \multirow{3}{*}{250} & 2 & 0.48 & 41.66 & 97.60 & 0.50 & 62.60 & 98.40 \\
\hline & & 4 & 0.33 & 55.26 & 98.12 & 0.45 & 66.00 & 98.48 \\
\hline & & 6 & 0.38 & 60.26 & 98.34 & 0.45 & 67.11 & 98.50 \\
\hline & \multirow{3}{*}{500} & 2 & 0.48 & 41.66 & 97.60 & 0.48 & 65.20 & 98.46 \\
\hline & & 4 & 0.36 & 58.33 & 98.28 & 0.36 & 82.50 & 98.78 \\
\hline & & 6 & 0.31 & 73.87 & 98.64 & 0.39 & 77.43 & 98.70 \\
\hline & \multirow{3}{*}{1000} & 2 & 0.55 & 36.36 & 97.25 & 0.38 & 82.36 & 98.78 \\
\hline & & 4 & 0.45 & 46.66 & 97.85 & 0.34 & 87.35 & 98.85 \\
\hline & & 6 & 0.39 & 58.71 & 98.29 & 0.36 & 83.88 & 98.80 \\
\hline \multirow{10}{*}{ AIT -2} & \multirow{2}{*}{25} & 2 & 1.15 & 17.39 & 94.25 & 0.95 & 32.94 & 96.96 \\
\hline & & 4 & 1.16 & 18.10 & 94.47 & - & - & - \\
\hline & \multirow{2}{*}{100} & 2 & 0.89 & 22.47 & 95.55 & 0.89 & 35.16 & 97.15 \\
\hline & & 4 & 0.78 & 26.92 & 96.28 & - & - & - \\
\hline & \multirow{2}{*}{250} & 2 & 0.59 & 33.89 & 97.05 & 0.53 & 59.05 & 98.30 \\
\hline & & 4 & 0.49 & 42.85 & 97.66 & - & - & - \\
\hline & \multirow{2}{*}{500} & 2 & 0.48 & 41.66 & 97.60 & 0.34 & 92.05 & 98.91 \\
\hline & & 4 & 0.39 & 53.84 & 98.14 & - & - & - \\
\hline & \multirow{2}{*}{1000} & 2 & 0.35 & 57.14 & 98.25 & 0.20 & 156.5 & 99.36 \\
\hline & & 4 & 0.38 & 55.26 & 98.19 & - & - & - \\
\hline
\end{tabular}

The data in the table show that the inhibitory efficiency of inhibitors increases in parallel with increasing inhibitory concentration and time at $200^{\circ} \mathrm{C}$ in $15 \% \mathrm{HCl}$ and $20 \% \mathrm{H}_{2} \mathrm{SO}_{4}$ solutions of AIT-1 and AIT-2. Based on the results, it can be said that the inhibitory properties of AIT-1 and AIT-2 inhibitors 
in sulfuric acid solution were higher than in hydrochloric acid solution. The melting rate of the metal decreases rapidly when a sample of steel grade St.3 is added to a solution of $15 \% \mathrm{HCl}$ and $20 \% \mathrm{H}_{2} \mathrm{SO}_{4}$ at a temperature of $200{ }^{\circ} \mathrm{C}$ with a concentration of $10^{-4} \mathrm{~mol} / 1(25 \mathrm{mg} / \mathrm{l})$ of inhibitors AIT-1 and AIT-2. Showed that the inhibition coefficient remained the same when the inhibitor concentration was increased from $4 \times 10^{-3}$ to $2 \times 10^{-3} \mathrm{~mol} / 1$ (100 to $\left.500 \mathrm{mg} / \mathrm{l}\right)$.
It has been shown that the effectiveness of inhibitors in sulfuric acid solution increases in parallel with the increase in inhibitor concentration. Showed that the inhibition coefficient of AIT- 1 and AIT-2 inhibitors $1 \times 10^{-4}$ and $4 \times 10^{-4} \mathrm{~mol} / 1$ increased with time. Table 2 below provides information on the protection levels of AIT-3 and AIT-4 inhibitors.

Efficacy of AIT-3 and AIT-4 inhibitors in 15\% $\mathrm{HCl}$ and $20 \% \mathrm{H}_{2} \mathrm{SO}_{4}$ solution at $20{ }^{\circ} \mathrm{C}$

Table 2.

\begin{tabular}{|c|c|c|c|c|c|c|c|c|}
\hline \multirow{2}{*}{$\begin{array}{l}\text { Ingib. } \\
\text { cipher }\end{array}$} & \multirow{2}{*}{$\begin{array}{c}\text { Ingib quan- } \\
\text { tity, mg/1 }\end{array}$} & \multirow{2}{*}{ Time hour } & \multicolumn{3}{|c|}{$15 \% \mathrm{HCl}$} & \multicolumn{3}{|c|}{$20 \% \mathrm{H}_{2} \mathrm{SO}_{4}$} \\
\hline & & & $K_{\Gamma / M^{2} \mathbf{Y}}$ & $\gamma$ & Z\% & $K_{r / M^{2} \Psi}$ & $\gamma$ & Z\% \\
\hline \multirow{6}{*}{ AIT -3 } & \multirow{3}{*}{50} & 2 & 1.77 & 11.31 & 91.15 & & & \\
\hline & & 4 & 1.50 & 14.00 & 92.86 & & & \\
\hline & & 6 & 1.17 & 19.61 & 94.90 & & & \\
\hline & \multirow{3}{*}{1000} & 2 & 0.94 & 21.29 & 95.30 & 0.40 & 78.25 & 98.72 \\
\hline & & 4 & 0.68 & 30.88 & 96.76 & 0.35 & 84.86 & 98.82 \\
\hline & & 6 & 0.59 & 38.88 & 97.42 & 0.52 & 58.12 & 98.91 \\
\hline \multirow{6}{*}{ AIT -4 } & \multirow{3}{*}{50} & 2 & 0.68 & 29.42 & 96.60 & 0.44 & 71.14 & 98.59 \\
\hline & & 4 & 0.58 & 36.20 & 97.23 & 0.26 & 114.2 & 99.12 \\
\hline & & 6 & 0.48 & 47.79 & 97.90 & 0.33 & 91.58 & 98.91 \\
\hline & \multirow{3}{*}{1000} & 2 & 0.50 & 40.02 & 97.50 & 0.17 & 184.0 & 99.46 \\
\hline & & 4 & 0.30 & 70.00 & 98.57 & 0.15 & 198.0 & 99.49 \\
\hline & & 6 & 0.30 & 76.46 & 98.69 & 0.14 & 215.8 & 99.54 \\
\hline
\end{tabular}

During the study, a mass reduction in the temperature range of 60-95.50S in a working system of $15 \%$ $\mathrm{HCl}$ and $20 \% \mathrm{H}_{2} \mathrm{SO}_{4}$ at a concentration of $1000 \mathrm{mg} / \mathrm{l}$ for 6 hours in a St. 3 sample of AIT-3 and AIT-4 inhibitors was determined by gravimetric measurement. Measurement of the mass reduction of the sample before the working solution and after a certain time in the working solution is useful in evaluating parameters such as corrosion rate $(\mathrm{g})$ and the effectiveness of inhibitors (Z\%). The following equation was used to determine these parameters and the results of the study were summarized in where: $\mathrm{m} 1$ is the weight of the sample before the study, in grams, $\mathrm{m}^{2}$ is the weight of the sample after the study, in grams, $s$ is the area of the sample in square meters $\left(\mathrm{m}^{2}\right)$ and $\mathrm{t}$ is the duration of the experiment, in hours. Efficacy results of inhibitors at different temperatures and $15 \% \mathrm{HCl}$ and $20 \%$ $\mathrm{H}_{2} \mathrm{SO}_{4}$ environments

Table 3.

\begin{tabular}{|c|c|c|c|c|c|c|c|c|c|}
\hline \multirow{2}{*}{$\begin{array}{l}\text { Ingib. } \\
\text { cipher }\end{array}$} & \multirow{2}{*}{$\begin{array}{c}\text { Environ- } \\
\text { ment\% }\end{array}$} & \multirow{2}{*}{$\begin{array}{c}\text { Inh } \\
\text { Amoмг } / \mathbf{A}\end{array}$} & \multirow{2}{*}{$\begin{array}{l}\text { Time } \\
\text { hour }\end{array}$} & \multicolumn{3}{|c|}{$60^{\circ} \mathrm{C}$} & \multicolumn{3}{|c|}{$95,5^{\circ} \mathrm{C}$} \\
\hline & & & & $K_{r / M}^{2}{ }^{2}$ & $\gamma$ & Z\% & $K_{r / M ~}^{2}$ & $\gamma$ & Z\% \\
\hline 1 & 2 & 3 & 4 & 5 & 6 & 7 & 8 & 9 & 10 \\
\hline \multirow{4}{*}{ AIT -3} & \multirow{4}{*}{$\begin{array}{l}\mathrm{HCl} \\
15 \%\end{array}$} & \multirow{4}{*}{1000} & 1 & - & $\begin{array}{ll}- \\
-\end{array}$ & - & 61.74 & 51.4 & 88.05 \\
\hline & & & 2 & 3.16 & 106.50 & 99.06 & & & \\
\hline & & & 4 & 3.01 & 122.53 & 99.18 & & & \\
\hline & & & 6 & 3.81 & 106.91 & 99.06 & & & \\
\hline
\end{tabular}




\begin{tabular}{|c|c|c|c|c|c|c|c|c|c|}
\hline 1 & 2 & 3 & 4 & 5 & 6 & 7 & 8 & 9 & 10 \\
\hline \multirow{4}{*}{ AIT -4} & \multirow{4}{*}{$\begin{array}{l}\mathrm{HCl} \\
15 \%\end{array}$} & \multirow{4}{*}{1000} & 1 & - & - & - & 68.66 & 46.19 & 79.84 \\
\hline & & & 2 & 7.07 & 51.46 & 98.06 & & & \\
\hline & & & 4 & 6.06 & 63.14 & 98.42 & & & \\
\hline & & & 6 & 6.74 & 59.20 & 98.31 & & & \\
\hline \multirow{4}{*}{ AIT -3} & \multirow{4}{*}{$\begin{array}{c}\mathrm{H}_{2} \mathrm{SO}_{4} \\
20 \%\end{array}$} & \multirow{4}{*}{1000} & 1 & - & - & - & 5.38 & 543.5 & 99.82 \\
\hline & & & 2 & 1.28 & 338.64 & 99.70 & & & \\
\hline & & & 4 & 1.35 & 372.07 & 99.73 & & & \\
\hline & & & 6 & 1.20 & 394.78 & 99.75 & & & \\
\hline \multirow{4}{*}{ AIT -4} & \multirow{4}{*}{$\begin{array}{c}\mathrm{H}_{2} \mathrm{SO}_{4} \\
20 \%\end{array}$} & \multirow{4}{*}{1000} & 1 & - & - & - & 8.30 & 351.6 & 99.72 \\
\hline & & & 2 & 3.01 & 144.01 & 99.31 & & & \\
\hline & & & 4 & 3.37 & 149.05 & 99.33 & & & \\
\hline & & & 6 & 2.90 & 163.36 & 99.39 & & & \\
\hline
\end{tabular}

Raising the temperature to $600 \mathrm{~S}$ leads to an increase in the inhibition rate even in $15 \% \mathrm{HCl}$ and $20 \%$ $\mathrm{H}_{2} \mathrm{SO} 4$ media of all inhibitors under study. However, raising the temperature to $95.5^{\circ} \mathrm{C}$ and above indicates that the inhibitors being studied in the hydrochloric acid environment are shifting in the direction of decreasing inhibition. However, an increase in temperature to $95.50 \mathrm{C}$ was found to give a positive result (99.72\%) for the AIT-4 inhibitor in a sulfuric acid environment. The protective properties of the metals of the compounds under study are stable over time in hydrochloric and sulfuric acid environments. The data obtained show that the inhibitors studied slow down the corrosion rate by $12-32$ times in an aggressive environment of hydrochloric acid at a dose of $50 \mathrm{mg} / 1$, while at a rate of $1000 \mathrm{mg} / 1$ slow down the corrosion rate by 75-140 times. Similarly, it was found that the protective properties of the inhibitors under study in hydrochloric and sulfuric acids increase periodically with increasing temperature.

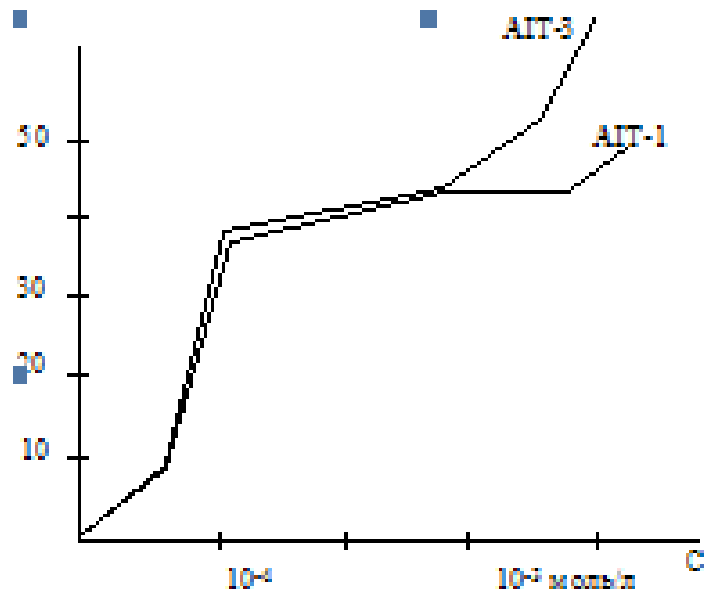

1-grafik. Tiaindan va tiaxrom an am inoketonlari qatori ingibitorlarining HCl m uhitida gi korroziyani tom ozlash

- koeffitsentining konantriyaga bog liqligi

Figure 1. shows the dependence of the inhibitor of the series of thiachromanic anions on the corrosion inhibition coefficient in the $\mathrm{H}_{2} \mathrm{SO}_{4}$ medium

Figure 1 below shows a graph of the correlation inhibition coefficient of the corrosion inhibitors of

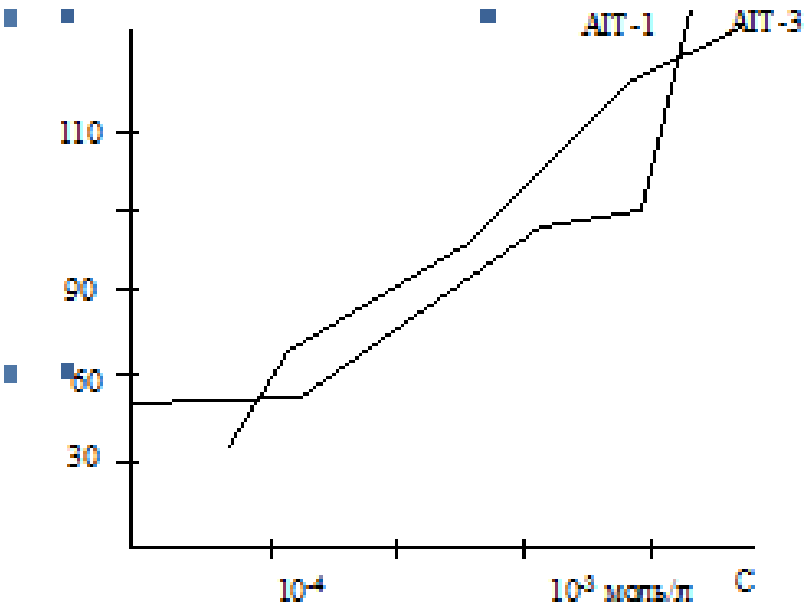

2-grafik. Tiaindan va tiyaxroman aminoketonl ari qatori ingibitorlarining $\mathrm{H}_{2} \mathrm{~S} \mathrm{O}_{4}$ muhitida korroziyani tormozlash koeffitsentining konentrasiyag a bog'liqligi

Figure 2. shows the dependence of the inhibitor of the series of thiachromanic anions on the corrosion inhibition coefficient in the $\mathrm{H}_{2} \mathrm{SO}_{4}$ medium

the corrosion inhibitors AIT-1 and AIT-3 containing the thiain and thiachroman fragment in the 
hydrochloric acid environment. The graph of the corrosion inhibition coefficient of the inhibitors studied above in the sulfuric acid environment depends on the inhibitor concentration.

The process of time-dependent reduction of the mass in the presence of an inhibitor in a $20 \%$
$\mathrm{H}_{2} \mathrm{SO}_{4}$ solution of the St. 3 sample obtained for the study can be represented by the image in Fig. 1. As can be seen from the figure, the melting rate of a steel sample in a solution with an inhibitor relative to a solution without an inhibitor significantly reduced.

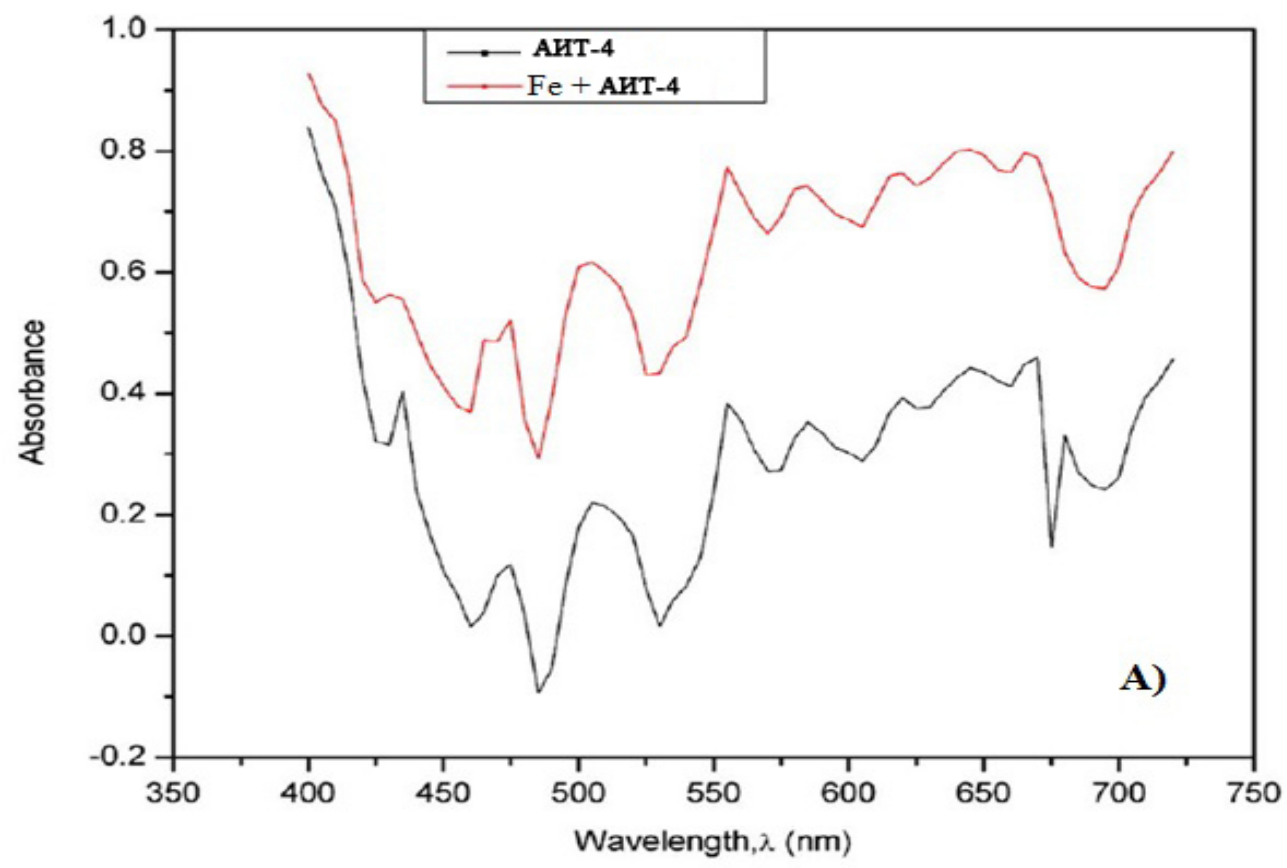

Figure 1 Decrease in mass of steel St. 3 in $20 \% \mathrm{H}_{2} \mathrm{SO}_{4}$ solution over time

The UV spectra of this solution were analyzed to confirm the formation of an In-Fe complex in a system containing $1000 \mathrm{mg} / \mathrm{l}$ AIT-4 inhibitor in 1 molar sulfuric acid obtained as a working solution.

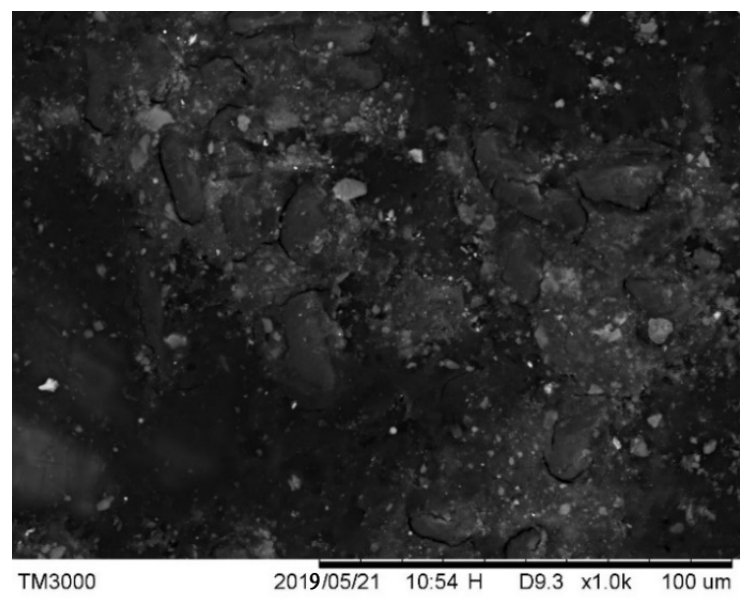

Without inhibitors in a solution
UV spectra were obtained in the absence of an inhibitor in the working solution and $6 \mathrm{~h}$ after the addition of the inhibitor. Comparative images of these UV spectra are shown in (Figure 2).

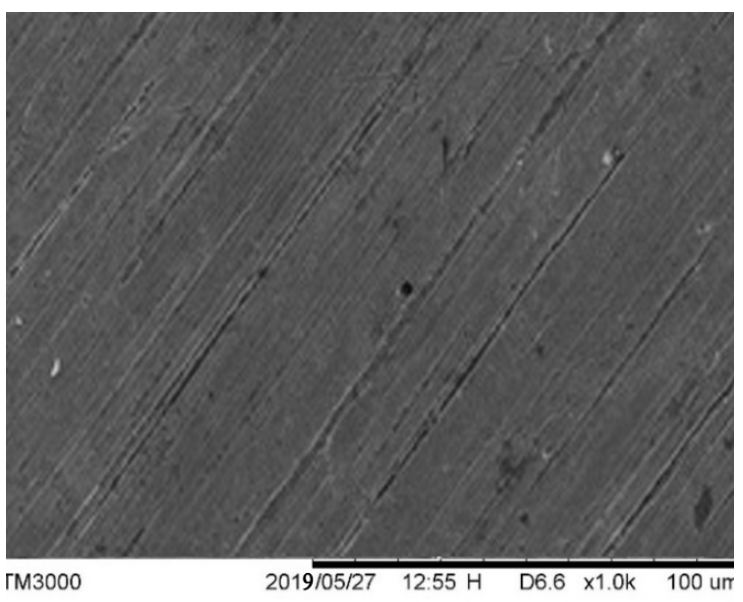

$1 \mathrm{M} \mathrm{HCl}$ with Inhibitor AIT-4 of $1 \mathrm{M} \mathrm{NCl}$

Figure 3. SEM-microphotography of Pulat St.3 sample 
The figure shows the absorption values and the deviation of their intensity. After immersion of the steel in the solution, an increase in absorption for the AIT-4 inhibitor is observed. This indicates the formation of a mutually stable complex between the $\mathrm{Fe} 2+$ ions and the functional-active groups of the inhibitor. The formation of this complex may be the cause of the observed deviation in the values of the absorption process and its intensity, which in turn leads to the anticorrosive activity of the inhibitor. In order to confirm the effectiveness of AIT-4 as a corrosion inhibitor, the images in (Figure 3) were obtained using SEM. As can be seen from the figure, the image of a steel sample lowered into the working system without the addition of an inhibitor reflected many cracks and abrasions on the steel surface. The image of the same steel ngamuna in the working solution of the inhibitor-added system shows that there are no cracks of the above appearance and that the erosion is not noticeable at all.

Thus, during the gravimetric study of the anticorrosive properties of the inhibitors studied, it was found that they are inhibitors that give good results to the corrosion process that takes place in the acidic environment. The binding of the sulfur atom in all synthesized inhibitors to the aromatic ring on the one hand and the poluaromatic ring on the other shows that the inhibitor molecules studied in these corrosive aggressive systems are capable of forming strong chemisorption-type bonds with structural materials.

\section{References:}

1. Kokalj A., Peljhan S., Finšgar M., Milošev I. What determines the inhibition effectiveness of ATA, BTAH, and BTAOH corrosion inhibitors on copper., J Am. Chem. Soc.- 132. 2010.- P. 16657-16668.

2. Finšgar M., Kek D., Merl, 2-mercaptobenzoxazole as a copper corrosion inhibitor in chloride solution: electrochemistry, 3D-profilometry, and XPS surface analysis, Corros. Sci.- 80. 2014.- P. 82-95.

3. Nešic' S., Sun W. 2.25 - Corrosion in acid gas solutions, in: J.A.R. Tony (Ed.), Shreir's Corrosion, Elsevier, Oxford, 2010.- P. 1270-1298. 